\title{
Pedigree and genomic evaluation of pigs using a terminal-cross model
}

\author{
Llibertat Tusell $^{1 *}$, Hélène Gilbert ${ }^{1}$, Juliette Riquet ${ }^{1}$, Marie-José Mercat ${ }^{2}$, Andres Legarra $^{1}$ and Catherine Larzul ${ }^{1}$
}

\begin{abstract}
Background: In crossbreeding schemes, within-line selection of purebreds is performed mainly to improve the performance of crossbred descendants under field conditions. The genetic correlation between purebred and crossbred performance is an important parameter to be assessed because purebred performance can be a poor predictor of the performance of crossbred offspring. With the availability of high-density markers, the feasibility of using crossbred information to evaluate purebred candidates can be reassessed. This study implements and applies a single-step terminal-cross model (GEN) to real data to estimate the genetic parameters of several production and quality traits in pigs.

Methods: Piétrain sires were mated with Piétrain and Large White dams to produce purebred and crossbred male half-sib piglets; growth rate, feed conversion ratio, lean meat, pH of longissimus dorsi muscle, drip loss and intramuscular fat content were recorded on all half-sibs. Animals were genotyped using the Illumina Porcine SNP60 BeadChip. The genetic correlation between purebred and crossbred performance was estimated separately for each trait. Purebred animals were evaluated using an animal model, whereas the additive genetic effect of a crossbred individual was decomposed into the additive effects of the sire and dam and a Mendelian sampling effect that was confounded with the residual effect. Genotypes of the Piétrain animals were integrated in the genetic evaluation by using a single-step procedure. As benchmarks, we used a model that was identical to GEN but only accounted for pedigree information (PED) and also two univariate single-step models (GEN_UNI) that took either purebred or crossbred performance into account.
\end{abstract}

Results: Genetic correlations between purebred and crossbred performance were high and positive for all traits $(>0.69)$. Accuracies of estimated breeding values of genotyped sires and purebred offspring that were obtained with the GEN model outperformed both those obtained with the PED and the GEN_UNI models. The use of genomic information increased the predictive ability of the GEN model, but it did not substantially outperform the GEN_UNI models.

Conclusions: We present a single-step terminal-cross model that integrates genomic information of purebred and crossbred performance by using available software. It improves the theoretical accuracy of genetic evaluations in breeding programs that are based on crossbreeding.

\section{Background}

The use of crossbreeding in breeding schemes reduces within-line inbreeding, and the resulting heterosis and breed complementarity have favorable effects on traits of commercial interest in crossbred (CB) animals. In

\footnotetext{
*Correspondence: Ilibertat.tusell-palomero@toulouse.inra.fr

${ }^{1}$ GenPhySE, Université de Toulouse, INRA, INPT, INP-ENVT, Castanet

Tolosan, France

Full list of author information is available at the end of the article
}

crossbreeding schemes, individuals from the purebred (PB) parental lines are commonly selected in highlysanitized environments in order to improve the performance of their $\mathrm{CB}$ descendants under field conditions, as a correlated response. In some cases, due to genetic and environmental differences between nucleus and field conditions, the performance of nucleus $\mathrm{PB}$ animals can be a poor predictor of the field performance of their $\mathrm{CB}$ descendants, which reduces the efficiency of the breeding program in terms of genetic progress at the commercial 
level [1]. Thus, it is important to determine the nature of the genetic correlation between $\mathrm{PB}$ and $\mathrm{CB}$ performance and their corresponding heritabilities to assess the interest of using $\mathrm{CB}$ information to evaluate $\mathrm{PB}$ animals for CB performance [2].

The theory on which selection for $\mathrm{CB}$ performance is based was largely developed and discussed many years ago [3], but until now, the use of CB information to evaluate the $\mathrm{PB}$ parental lines has not resulted in a clear advantage for within-line PB selection and has not been widely implemented in practice. This is primarily due to practical difficulties in tracing $\mathrm{CB}$ pedigrees and performances back to their PB parents. However, with the availability of high-density single nucleotide polymorphism (SNP) genotype data, this scenario now needs to be reevaluated. The use of genomic information can improve response to selection by increasing the accuracy of genetic evaluations, increasing the number of candidates for selection, performing genetic evaluations at an earlier age than with traditional approaches, lowering the rate of inbreeding, avoiding the need for pedigree information to connect $\mathrm{PB}$ and $\mathrm{CB}$ individuals (depending on the method used), and accommodating non-additive genetic effects that can impact $\mathrm{CB}$ performance (i.e. dominance and heterosis) $[4,5]$.

In this study, we developed and tested on a real pig dataset a single-step terminal-cross model to estimate the genetic parameters of several production and quality traits. This model is based on the model of Wei and van der Werf [6], with an extension to include PB genotypes. The theoretical accuracies of the estimated breeding values from the mixed model equations, a pedigree-based terminal cross model, and two univariate single-step models for $\mathrm{PB}$ and $\mathrm{CB}$ performances are provided. Predictive ability of the models is also evaluated in cross-validation.

\section{Methods}

\section{Animals and data}

The experiment was conducted according to the French guidelines for animal care and use (http://ethique.ipbs.fr/ $\mathrm{sdv} /$ charteexpeanimale.pdf).

Animals were produced by the four French breeding companies of the Bioporc group (ADN, Choice Genetics France, Gène+, Nucléus) involved in the UtOpIGe project ANR-10-GENOM_BTV-015, which aims at investigating the feasibility of implementing genomic selection in pyramidal breeding schemes. A large number of traits that are difficult to measure under field conditions were recorded in several $\mathrm{PB}$ and $\mathrm{CB}$ populations that were raised in the same environment. In a first step, PB Piétrain and CB Piétrain $\times$ Large White animals were produced on selection and multiplication farms and tested at a single test station. In a second step, PB Piétrain sires were mated with sows of various $\mathrm{CB}$ and $\mathrm{PB}$ populations in order to test pigs that represent usual commercial production crosses at the same test station and to validate the results obtained from the first step.

The present analyses involved only animals generated in the first step of the project, including 90 Piétrain boars (the offspring of 69 sires) and their descendants: $654 \mathrm{~PB}$ Piétrain and 716 CB Piétrain $\times$ Large White entire male piglets. Piétrain pigs are renowned for their very high yield of lean meat, whereas Large White pigs are reputed for their excellent maternal instinct, large litter size and high milk production. The $\mathrm{PB}$ and the $\mathrm{CB}$ descendants entered the test station facilities of Le Rheu (France) at approximately 5 weeks of age and were slaughtered at a fixed weight of $110 \mathrm{~kg}$ (at 5-6 months of age).

The following traits were recorded: average daily gain from the beginning ( $35 \mathrm{~kg})$ to the end $(110 \mathrm{~kg})$ of the test period (ADG), feed conversion ratio (FCR), \% lean meat (LM), $\mathrm{pH}$ of the longissimus dorsi muscle ( $\mathrm{pH})$, drip loss (DL), and intramuscular fat (IMF). Data were obtained in accordance with the national regulations on the welfare of animals used in research.

At the slaughterhouse, carcasses were chilled in a cooling room at $4{ }^{\circ} \mathrm{C}$ for $24 \mathrm{~h}$ and right half-carcasses were cut [7]. LM was estimated from a linear combination of the weights of cuts that were expressed as a percentage of the cold half-carcass weight for ham, loin and backfat [8]. Ultimate $\mathrm{pH}$ of the longissimus dorsi muscle was measured using a Xerolyt electrode (Mettler-Toledo, Australia) and a Sydel pH meter (Sydel, France). DL was measured on a sample of loin of about $130 \mathrm{~g}$ (at the 13th lumbar vertebra). After weighing the samples, they were placed directly in a polystyrene tray, covered with polyethylene film and stored at $4{ }^{\circ} \mathrm{C}$ for $48 \mathrm{~h}$, such that each slice formed a 40-degree angle with the horizontal plane. Then, the samples were wiped gently and weighed again. The DL was quantified as the difference between the two weights, expressed as a percentage of the initial weight. After DL measurement, the samples were frozen until IMF was measured by magnetic resonance imaging [9].

A separate pedigree file was constructed for each PB line. Piétrain and Large White pedigrees were constructed up to five generations back from the Piétrain boars for which data were available as $\mathrm{PB}$ or sires of $\mathrm{CB}$ offspring and from the Large White sows for which data were available as dams of CB offspring, respectively.

The 90 Pietrain boars and their PB descendants were genotyped using the Illumina Porcine SNP60 BeadChip (Illumina, Inc., San Diego). SNPs with a call rate lower than 0.90 and a minor allele frequency lower than 0.05 were removed. For the remaining SNPs, the very few missing genotypes were imputed using a naïve method 
that sampled the genotypes with probability weights based on allele frequencies at each locus. Animals with a call rate lower than 0.90 and progeny that displayed Mendelian inconsistencies with their parents were discarded. Summary statistics of the phenotypes, pedigrees and genotypes are in Tables 1 and 2. Given that the number of animals with records differed for each trait, data were edited separately for each trait. Thus, the number of SNPs retained for the analyses differed slightly between traits.

\section{Statistical analyses}

$\mathrm{PB}$ and $\mathrm{CB}$ phenotypes for a trait were considered as two different traits. They were analyzed jointly by adapting the terminal-cross model proposed by Wei and van der Werf (see Appendix 2 in [6]) by either using pedigree information only or by combining pedigree and genomic information in a single-step procedure [10-12]. The model used here is a simplification of the model of Christensen et al. [13], who considered the inclusion of CB genotypes.

\section{Pedigree-based terminal-cross model}

In matrix notation, the $\mathrm{PB}$ and $\mathrm{CB}$ records of a given trait in a pedigree-based terminal-cross model (PED) can be represented as follows:

$$
\begin{aligned}
{\left[\begin{array}{l}
\mathbf{y}_{A} \\
\mathbf{y}_{C}
\end{array}\right]=} & {\left[\begin{array}{cc}
\mathbf{x}_{A} & 0 \\
0 & \mathbf{X}_{C}
\end{array}\right]\left[\begin{array}{l}
\mathbf{b}_{A} \\
\mathbf{b}_{C}
\end{array}\right]+\left[\begin{array}{cc}
\mathbf{w}_{A} & 0 \\
0 & \mathbf{W}_{C}
\end{array}\right]\left[\begin{array}{l}
\mathbf{p}_{A} \\
\mathbf{p}_{C}
\end{array}\right] } \\
& +\left[\begin{array}{ccc}
\mathbf{z}_{A} & 0 & 0 \\
0 & \mathbf{Z}_{A C} & \mathbf{Z}_{B C}
\end{array}\right]\left[\begin{array}{l}
\mathbf{u}_{A A} \\
\mathbf{u}_{A C} \\
\mathbf{u}_{B C}
\end{array}\right]+\left[\begin{array}{l}
\mathbf{e}_{A} \\
\mathbf{e}_{C}
\end{array}\right]
\end{aligned}
$$

where $\mathbf{y}_{k}$ is a vector of phenotypes for the PB Piétrain (for $k=A$,) and CB Piétrain $\times$ Large White individuals (for $k=C), \mathbf{b}_{k}$ is a vector of systematic effects, $\mathbf{p}_{k}$ is a vector of the random pen effects (nested within batch), and $\mathbf{e}_{k}$ is a vector of residual effects. $\mathbf{X}_{k}, \mathbf{W}_{k}$ and $\mathbf{Z}_{A}, \mathbf{Z}_{A C}$ and $\mathbf{Z}_{B C}$ are incidence matrices that assign systematic, pen and additive genetic effects, respectively, to the phenotypes. A brief description of the effects included in the model for each trait analyzed is in Table 3 . Vector $\mathbf{u}_{A A}$ is the vector of additive genetic effects for the PB pigs. The additive genetic effect for the $\mathrm{CB}$ individuals $\left(\mathbf{u}_{C C}\right)$ is decomposed into the additive gametic effects for $\mathrm{CB}$ performance of their corresponding Piétrain sires and Large White dams ( $\mathbf{u}_{A C}$ and $\mathbf{u}_{B C}$, respectively) and the corresponding sire and dam Mendelian sampling effects $\left(\phi_{A}\right.$ and $\phi_{B}$, respectively):

$$
\mathbf{u}_{C C}=\mathbf{Z}_{A C} \mathbf{u}_{A C}+\mathbf{Z}_{B C} \mathbf{u}_{B C}+\boldsymbol{\phi}_{A}+\boldsymbol{\phi}_{B} .
$$

The Mendelian sampling effects cannot be estimated and are, therefore, included in the residual effect of the

Table 1 Summary statistics of the purebred/crossbred phenotype data

\begin{tabular}{|c|c|c|c|c|c|c|}
\hline & Growth rate & $\begin{array}{l}\text { Feed } \\
\text { conversion ratio }\end{array}$ & Lean meat & $\begin{array}{l}\mathrm{pH} \\
\text { longissimus dorsi }\end{array}$ & Drip loss & $\begin{array}{l}\text { Intramuscular } \\
\text { fat }\end{array}$ \\
\hline Number purebred offspring & 654 & 631 & 638 & 640 & 614 & 538 \\
\hline Number crossbred sires/dams & $90 / 306$ & $90 / 306$ & $90 / 306$ & $90 / 306$ & $90 / 304$ & $89 / 302$ \\
\hline Number animals in the Piétrain pedigree & 3084 & 3036 & 3052 & 3057 & 3007 & $2 / 900$ \\
\hline Number animals in the Large White pedigree & 2686 & 2686 & 2686 & 2686 & 2676 & $2 / 677$ \\
\hline Number SNPs, after editing & 39,672 & 39,673 & 39,673 & 39,681 & 39,650 & 39,643 \\
\hline $\begin{array}{l}\text { Number genotyped PB offspring individuals/ } \\
\text { sires, after editing }\end{array}$ & $635 / 89$ & $616 / 89$ & $626 / 89$ & $628 / 89$ & 603/89 & $530 / 88$ \\
\hline
\end{tabular}

\begin{tabular}{lllllll}
\hline & Growth rate & $\begin{array}{l}\text { Feed conversion } \\
\text { ratio }\end{array}$ & Lean meat & $\begin{array}{l}\text { pH } \\
\text { longissimus dorsi }\end{array}$ & $\begin{array}{l}\text { Drip loss } \\
\text { Intramuscular } \\
\text { fat }\end{array}$ \\
\hline Units & g/day & $\mathrm{kg} / \mathrm{kg}$ & $\%$ & $\mathrm{pH}$ units & $\%$ & $\%$ \\
Minimum & $511.1 / 592.6$ & $1.83 / 1.67$ & $54.8 / 57.7$ & $5.29 / .27$ & $1.35 / 0.74$ & $0.45 / 0.23$ \\
Mean & $938.5 / 1038.0$ & $2.29 / 2.25$ & $64.05 / 62.48$ & $5.58 / 5.62$ & $7.26 / 4.87$ & $1.14 / 1.21$ \\
Maximum & $1214.9 / 1291.0$ & $3.20 / 2.7$ & $67.80 / 67.6$ & $6.42 / 6.51$ & $16.54 / 15.50$ & $2.15 / 2.26$ \\
Coefficient of variation & $0.11 / 0.09$ & $0.07 / 0.07$ & $0.02 / 0.03$ & $0.03 / 0.03$ & $0.38 / 0.40$ & $0.21 / 0.21$ \\
Number of records & $654 / 716$ & $631 / 709$ & $638 / 13$ & $640 / 714$ & $614 / 689$ & $538 / 650$ \\
\hline
\end{tabular}

Table 2 Summary statistics of the purebred/crossbred pedigree and genotype data

SNP single-nucleotide polymorphism, $P B$ purebred, $C B$ crossbred 
Table 3 Systematic and permanent environmental random effects included in the models of analysis for each trait

\begin{tabular}{|c|c|c|c|c|c|c|}
\hline \multirow[t]{2}{*}{ Effect } & \multicolumn{6}{|l|}{ Trait } \\
\hline & Growth rate & Feed conversion ratio & Lean meat & $\mathrm{pH}$ longissimus dorsi & Drip loss & Intramuscular fat \\
\hline $\begin{array}{l}\text { Weight at the beginning } \\
\text { of the control period }\end{array}$ & Covariate & Covariate & - & - & - & - \\
\hline Hot carcass weight & - & - & Covariate & - & - & - \\
\hline Weight at slaughter & - & - & - & Covariate & Covariate & Covariate \\
\hline Date of slaughter & - & - & - & 52 levels & 50 levels & 49 levels \\
\hline Batch & 11 levels & 11 levels & 11 levels & 11 levels & 11 levels & 11 levels \\
\hline Pen effect nested within batch & 132 levels & 132 levels & 132 levels & - & - & - \\
\hline
\end{tabular}

CB part of the model (Eq. 1). Note that $\mathbf{u}_{A A}$ and $\mathbf{u}_{A C}$ have the same dimension and that two genetic effects are assigned to each PB Piétrain animal.

The variance-covariance structure of additive genetic effects was assumed to follow:

$$
\operatorname{var}\left[\begin{array}{l}
\mathbf{u}_{A A} \\
\mathbf{u}_{A C} \\
\mathbf{u}_{B C}
\end{array}\right]=\left[\begin{array}{ccc}
\mathbf{A}_{A} \sigma_{A}^{2} & \mathbf{A}_{A} \sigma_{A(A C)} & 0 \\
\mathbf{A}_{A} \sigma_{A(A C)} & \mathbf{A}_{A} \sigma_{A C}^{2} & 0 \\
0 & 0 & \mathbf{A}_{B} \sigma_{B C}^{2}
\end{array}\right],
$$

where $\mathbf{A}_{A}$ and $\mathbf{A}_{B}$ are the relationship matrices for the Piétrain and the Large White individuals, respectively, computed based on their corresponding pedigrees. $\sigma_{A}^{2}$ is the additive genetic variance of the Piétrain line for $\mathrm{PB}$ performance, $\sigma_{A C}^{2}$ and $\sigma_{B C}^{2}$ are the additive genetic variances of the additive genetic contributions of Piétrain and Large White breeds, respectively, to $\mathrm{CB}$ performance, which are equal to one quarter of the genetic variance in a traditional sense (see below). Finally, $\sigma_{A(A C)}$ is the additive genetic covariance between $\mathrm{PB}$ and $\mathrm{CB}$ performance of the Piétrain animals. For the maternal line, only the additive genetic variance for $\mathrm{CB}$ performance was estimated. There were no correlations between pen effects, $\mathbf{P}=\operatorname{diag}\left(\sigma_{p A}^{2} \sigma_{p C}^{2}\right)$ and between residual effects, $\mathbf{R}=\operatorname{diag}\left(\sigma_{e A}^{2} \sigma_{e C}^{2}\right)$, or between these effects and other random effects.

\section{Single-step terminal-cross model}

The form of the single-step terminal-cross model (GEN) is the same as that of Eq. (1). In the GEN model, the inverse of the numerator relationship matrix of the Piétrain line $\left(\mathbf{A}_{A}^{-1}\right)$ that was used in the mixed model equations to estimate the breeding values [14] is replaced by the inverse of the $\mathbf{H}$ matrix $\left(\mathbf{H}^{-1}\right)$ that combines both the genomic $(\mathbf{G})$ and the pedigree-based relationship matrices allowing the joint genetic evaluation of genotyped and non-genotyped animals $[12,15]$ :

$$
\mathbf{H}^{-1}=\mathbf{A}_{A}^{-1}+\left[\begin{array}{lc}
0 & 0 \\
0 & \mathbf{G}^{-1}-\mathbf{A}_{(\boldsymbol{A}) 22}^{-1}
\end{array}\right],
$$

where $\mathbf{G}^{-1}$ is the inverse of the genomic relationship matrix and $\mathbf{A}_{(\boldsymbol{A}) 22}^{-1}$ is the inverse of the pedigree-based relationship matrix of the genotyped animals.

For PB Piétrain individuals (i.e. PB descendants and their sires), $\mathbf{G}$ was calculated following the default singlestep procedure as programmed in blupf90 (http://nce. ads.uga.edu/wiki/lib/exe/fetch.php?media=blupf90_all1. pdf). First, Van Raden's equation [16] was used:

$$
\mathbf{G}^{*}=\frac{(\mathbf{X}-\mathbf{E})(\mathbf{X}-\mathbf{E})^{\prime}}{2 \sum_{j=1}^{p} q_{j}\left(1-q_{j}\right)}
$$

where SNP genotypes were coded as 0,1 , and 2 for animals that were homozygous for the minor allele, heterozygous, and homozygous for the other allele, respectively. This leads to $\mathbf{X}=\left\{x_{i j}\right\}$, a matrix of dimension $n \times p(i=1, \ldots, n$ and $j=1, \ldots, p$, with $n$ being the number of genotyped individuals and $p$ the number of SNPs), $q_{j}$ is the frequency of the minor allele of the $j$ th SNP. Each column of matrix $\mathbf{E}$ contains twice the expected genotype frequencies at each locus. Given that the allele frequencies from the base population under Hardy-Weinberg equilibrium were not available, the allele frequencies among the genotyped animals were used to calculate the expected genotype frequencies.

Then, $\mathbf{G}^{*}$ was adjusted to match the average level of inbreeding and coancestries of $\mathbf{A}_{(A) 22}$, as described by Christensen et al. [17]. Finally, $\mathbf{G}=0.95 \mathbf{G}^{*}+0.05 \mathbf{A}_{(A) 22}$ to make $\mathbf{G}$ invertible. Similar to the PED model, the GEN model used only pedigree information $\left(\mathbf{A}_{B}\right)$ to estimate $\sigma_{B C}^{2}$.

\section{Single-step univariate models}

Single-step univariate models (GEN_UNI) were also run separately for $\mathrm{PB}$ and $\mathrm{CB}$ phenotypes by including the same effects as for the GEN model:

$$
\mathbf{y}_{A}=\mathbf{X}_{A} \mathbf{b}_{A}+\mathbf{W}_{A} \mathbf{p}_{A}+\mathbf{Z}_{A} \mathbf{u}_{A A}+\mathbf{e}_{A},
$$




$$
\mathbf{y}_{C}=\mathbf{X}_{C} \mathbf{b}_{C}+\mathbf{W}_{C} \mathbf{p}_{C}+\mathbf{Z}_{A C} \mathbf{u}_{A C}+\mathbf{Z}_{B C} \mathbf{u}_{B C}+\mathbf{e}_{C} .
$$

\section{Parameter inference}

A Bayesian framework was adopted for inference to express uncertainty about the unknowns through the use of probability density functions. Flat prior distributions were assumed for the parameters of the systematic effects and the (co)variance components. The Gibbs sampler algorithm was used to estimate the marginal posterior distributions of the systematic effects and the (co)variance components using the GIBBS1f90 software developed by Misztal et al. [18]. Single chains of 250,000, 500,000 and 250,000 iterations were run by discarding the first 25,000 , 50,000 and 25,000 iterations of each chain for the PED, GEN and GEN_UNI models, respectively, for each analyzed trait. Longer chains were run for the GEN models due to the less sparse structure of the single-step equations, which may preclude good mixing of the chains. The number of discarded samples was, in all cases, larger than the required burn-in that was determined by visual inspection and by the procedures of Raftery and Lewis [19] and Geweke [20]. Samples of the parameters of interest were saved every ten rounds and used to compute summary statistics for the marginal posterior distributions.

\section{Rescaling additive genetic contributions of sires and dams to the crossbred trait}

Because $\mathrm{CB}$ offspring performance includes only half of the breeding values for $\mathrm{CB}$ performance of their $\mathrm{PB}$ parents, Wei and van der Werf [6] assigned 0.5 instead of 1 to the non-zero elements of the design matrices $\mathbf{Z}_{A C}$ and $\mathbf{Z}_{B C}$ in Eq. (1). In our case, we assigned ones to the non-zero elements of the incidence matrices for practical implementation purposes. Thus, posterior rescaling of the genetic variances was required to obtain proper (co)variance estimates. For example on the paternal side, $\mathbf{u}_{A C}$ is equal to half the additive genetic effect of the sire for $\mathrm{CB}$ performance. To recover the corresponding paternal breeding value, each gametic contribution was multiplied by 2 , i.e. $\mathbf{u}_{A C}^{*}=2 \mathbf{u}_{A C}$. This, in turn, leads to rescaling the parental genetic variance as $\operatorname{var}\left(\mathbf{u}_{A C}^{*}\right)=4 \operatorname{var}\left(\mathbf{u}_{A C}\right)=4 \sigma_{A C}^{2}$ and the additive genetic covariance as $\sigma_{A(A C)}^{\prime \prime}=2 \sigma_{A(A C)}$. The same rescaling also applies for the genetic variance on the maternal side.

\section{Theoretical accuracies of estimated breeding values}

The posterior mean (co)variance components obtained with the Gibbs sampler for the GEN model were used as the true values to obtain best linear unbiased prediction (BLUP) estimates for the breeding values in the different models using the BLUPf90 software [18]. The theoretical accuracy of the estimated breeding value for the $i$ th individual for the $k$ th $(k=A, A C)$ performance with the $m$ th model $\left(m=G E N, P E D, G E N \_U N I\right)\left(E B V_{i, k, m}\right)$ was calculated as [13]:

$$
R_{i, k, m}=\sqrt{1-\frac{P E V_{i, k, m}}{\left(1+F_{i}\right) \sigma_{k}^{2}}},
$$

where $P E V_{i, k, m}$ is the prediction error variance of its $E B V_{i, k, m}, F_{i}$ is the inbreeding coefficient of individual $i$, which was computed from the pedigree using the INBUPGf90 software [21], and $\sigma_{k}^{2}$ is the additive genetic variance of $\mathrm{PB}$ or $\mathrm{CB}$ performance. Theoretical accuracies of EBV were obtained for all sires and $\mathrm{PB}$ offspring and also for some PB descendants that were considered to be candidates for selection (one descendant if the sire had less than four male offspring and two otherwise). Theoretical accuracies of EBV for these candidates were obtained using BLUP by either masking or including their own phenotype, in order to reproduce a situation under commercial conditions where some traits are measured on candidates and other traits are measured on relatives that are housed in test stations.

\section{Assessment of predictive ability}

The ability of the models to predict yet-to-be observed phenotypes was compared using sixfold cross-validation. First, BLUP solution estimates for the systematic effects obtained with the GEN model were used to obtain adjusted phenotype records, separately for each trait. Second, sires were randomly split into six approximately equal subsets. All records of the offspring of a sire were assigned to its respective subset. BLUP parameters were estimated based on five of the six data subsets, referred to as the training set, and the predictive ability was assessed in the remaining dataset, which was used as the testing set and considered as the yet-to-be observed phenotypes of the candidate sires. The training-testing cycle was repeated six times by rotating the six subsets used for training and testing, with each subset used only once for testing and five times for training. The predictive ability of each model was evaluated using the average Pearson's correlation between observed and predicted phenotypes of the testing sets.

In addition, the EBV of sires for PB performance estimated with the GEN_UNI model were used to predict CB performance under the GEN_UNI CB model. This predictive ability was also assessed with the sixfold crossvalidation mentioned above.

\section{Results and discussion}

\section{Genetic parameters}

Genetic parameter estimates, ratios of variance components, and ratios of phenotypic variances obtained with the GEN model are in Table 4. Most of the estimated 
Table 4 Mean (highest posterior density interval at $95 \%$ ) of the marginal posterior distribution of genetic parameters estimated with the single-step model

\begin{tabular}{|c|c|c|c|c|c|c|c|c|}
\hline \multirow[t]{2}{*}{ Trait } & \multicolumn{8}{|l|}{ Parameter } \\
\hline & $\overline{h_{A}^{2}}$ & $t_{A C}^{2}$ & $t_{B C}^{2}$ & $r g_{A, A C}$ & $p_{A}^{2}$ & $p_{C}^{2}$ & $\sigma_{A}^{2}$ & $\sigma_{C}^{2}$ \\
\hline Growth rate & $\begin{array}{l}0.22 \\
{[0.05,0.37]}\end{array}$ & $\begin{array}{l}0.25 \\
{[0.03,0.45]}\end{array}$ & $\begin{array}{l}0.28 \\
{[0.12,0.44]}\end{array}$ & $\begin{array}{l}0.84 \\
{[0.45,1.00]}\end{array}$ & $\begin{array}{l}0.14 \\
{[0.06,0.23]}\end{array}$ & $\begin{array}{l}0.09 \\
{[0.02,0.16]}\end{array}$ & $\begin{array}{l}9151 \\
{[7954,10,418]}\end{array}$ & $\begin{array}{l}8028 \\
{[6813,9324]}\end{array}$ \\
\hline Feed conversion ratio & $\begin{array}{l}0.32 \\
{[0.20,0.46]}\end{array}$ & $\begin{array}{l}0.29 \\
{[0.13,0.46]}\end{array}$ & $\begin{array}{l}0.18 \\
{[0.05,0.32]}\end{array}$ & $\begin{array}{l}0.91 \\
{[0.72,1.00]}\end{array}$ & $\begin{array}{l}0.10 \\
{[0.03,0.18]}\end{array}$ & $\begin{array}{l}0.09 \\
{[0.03,0.16]}\end{array}$ & $\begin{array}{l}0.02 \\
{[0.02,0.03]}\end{array}$ & $\begin{array}{l}0.02 \\
{[0.02,0.02]}\end{array}$ \\
\hline Lean meat & $\begin{array}{l}0.41 \\
{[0.25,0.57]}\end{array}$ & $\begin{array}{l}0.30 \\
{[0.14,0.46]}\end{array}$ & $\begin{array}{l}0.28 \\
{[0.12,0.45]}\end{array}$ & $\begin{array}{l}0.69 \\
{[0.30,1.00]}\end{array}$ & $\begin{array}{l}0.04 \\
{[0.0001,0.08]}\end{array}$ & $\begin{array}{l}0.06 \\
{[0.01,0.12]}\end{array}$ & $\begin{array}{l}2.50 \\
{[2.19,2.82]}\end{array}$ & $\begin{array}{l}3.15 \\
{[2.75,3.59]}\end{array}$ \\
\hline $\mathrm{pH}$ longissimus dorsi & $\begin{array}{l}0.30 \\
{[0.17,0.36]}\end{array}$ & $\begin{array}{l}0.26 \\
{[0.16,0.40]}\end{array}$ & $\begin{array}{l}0.11 \\
{[0.02,0.22]}\end{array}$ & $\begin{array}{l}0.97 \\
{[0.83,1.00]}\end{array}$ & - & - & $\begin{array}{l}0.02 \\
{[0.02,0.02]}\end{array}$ & $\begin{array}{l}0.02 \\
{[0.02,0.03]}\end{array}$ \\
\hline Drip loss & $\begin{array}{l}0.57 \\
{[0.44,0.69]}\end{array}$ & $\begin{array}{l}0.21 \\
{[0.08,0.35]}\end{array}$ & $\begin{array}{l}0.15 \\
{[0.03,0.30]}\end{array}$ & $\begin{array}{l}0.89 \\
{[0.62,1.00]}\end{array}$ & - & - & $\begin{array}{l}6.21 \\
{[5.41,7.04]}\end{array}$ & $\begin{array}{l}3.38 \\
{[2.96,3.81]}\end{array}$ \\
\hline Intramuscular fat & $\begin{array}{l}0.31 \\
{[0.16,0.48]}\end{array}$ & $\begin{array}{l}0.34 \\
{[0.16,0.54]}\end{array}$ & $\begin{array}{l}0.25 \\
{[0.08,0.43]}\end{array}$ & $\begin{array}{l}0.82 \\
{[0.46,1.00]}\end{array}$ & - & - & $\begin{array}{l}0.05 \\
{[0.05,0.06]}\end{array}$ & $\begin{array}{l}0.07 \\
{[0.06,0.08]}\end{array}$ \\
\hline
\end{tabular}

$h_{A}^{2}=$ purebred heritability

$t_{i C}^{2}=$ ratio of variance of the parental allelic contribution in the crossbreds ( $i=A, B$ for Piétrain and Large White line, respectively) computed as $2 \sigma_{i}^{2} \sigma_{C}^{2}$ where $\sigma_{i C}^{2}$ is the additive genetic variance of the corresponding parental alleles in the crossbreds

$r g_{A, A C}=$ genetic correlation between purebred individual and sire line contribution in the crossbreds

$p_{j}^{2}=$ ratio of variance of common pen effect

$\sigma_{j}^{2}=$ phenotypic variances $(j=A, C$ for purebred Piétrain and crossbred, respectively)

heritabilities for traits related to $\mathrm{PB}$ performance were within the range of those obtained in previous studies on pigs [22-25], although an unusually high value was found for drip loss, i.e. 0.57 compared to published values, which range from 0.10 to 0.30 [26].

Estimated genetic correlations between PB Piétrain and $\mathrm{CB}$ performance of Piétrain sires were all positive and high and none of the highest $95 \%$ posterior density intervals $\left(\mathrm{HPD}_{95} \%\right)$ of the estimates included values below 0.30 . This indicates that most of the genetic variance observed for those traits is due to additive genes with no relevant dominance gene action and, possibly, no differences in gene frequency between the two lines, i.e. there is no strong genetic interaction between the Piétrain and Large White breeds. The magnitude and sign of the estimated genetic correlation between $\mathrm{PB}$ and $\mathrm{CB}$ performance are keys to decide the best strategy to evaluate $\mathrm{PB}$ animals for $\mathrm{CB}$ performance [2]. Hence, based on our results and the conditions under which this study was performed, selecting to improve traits within the paternal $\mathrm{PB}$ line, without accounting for $\mathrm{CB}$ information, would lead to an improvement in the $\mathrm{CB}$ population as a correlated response [27]. Whether the degree of this improvement would overcome the gain of incorporating CB performance needs to be further addressed. Various ranges of genetic correlation estimates between $\mathrm{PB}$ and $\mathrm{CB}$ performances have been reported in the literature using different pedigree-based approaches. Apart from a few exceptions, they range from moderate to high values for production traits such as lifetime daily gain, feed conversion ratio, back fat thickness, and weight (see reviews in $[1,28,29]$. For genetic correlations that differ from 1, other selection strategies might be more appropriate to improve genetic response in $\mathrm{CB}$ descendants, for example: (1) evaluating the PB lines based on $\mathrm{CB}$ information only (recurrent selection and reciprocal recurrent selection [3]), (2) combining both $\mathrm{PB}$ and CB information into a weighted selection index [30,31], (3) using a terminal-cross model $[6,13]$, or (4) using a multiple-trait approach with one additive effect [32], although the latter can lead to biased estimates of $\mathrm{PB} C \mathrm{CB}$ covariance [33]. Genetic correlations between PB and CB performances can differ from 1 if non-additive genetic effects, such as dominance are present and allele frequencies differ between the parental lines [34]. Genetic effects can also vary with the environment in which $\mathrm{PB}$ and $\mathrm{CB}$ individuals are raised, which can also contribute to genetic correlations differing from 1 . Such situations are common in pig breeding, with PB lines reared and evaluated on nucleus farms that are defined by a high health status environment and $\mathrm{CB}$ pigs raised on commercial farms under field conditions. In the current study, all animals were raised at the same time and in the same test station facility and differed only in the genetic origin of the dams. Thus, the environment was simply defined by the breeding type [35].

The ratios of genetic variance for $\mathrm{CB}$ performance for the sire and dam lines were of similar magnitude across the traits, although they tended to be slightly higher for the sire line for FCR, pH and IMF (Table 4). Heritabilities 
for $\mathrm{CB}$ performance are the sum of the ratios of paternal and maternal line genetic contributions (Table 4, $\left.t_{\mathrm{AC}}^{2}+t_{\mathrm{BC}}^{2}\right)$ and were approximately of the same magnitude as heritabilities for $\mathrm{PB}$ performance for FCR and $\mathrm{pH}$, but were higher for ADG, LM and IMF, and lower for DL. Some studies have reported lower heritabilities for $\mathrm{CB}$ than for $\mathrm{PB}$ performance, which is mainly due to a less controlled environment for the CB field data compared with the PB station data [36] but this does not apply to our study.

The additive genetic variances $\left(h_{A}^{2} \sigma_{A}^{2}\right.$ and $t_{A C}^{2} \sigma_{C}^{2}+t_{B C}^{2} \sigma_{C}^{2}$ for $\mathrm{PB}$ and $\mathrm{CB}$ performance, respectively; Table 4) were slightly higher for crossbred than for $\mathrm{PB}$ performance for most of the analyzed traits, which could indicate subtle differences in gene combinations affecting the traits in the two populations, and a slightly stronger influence of non-additive genetic effects, such as dominance, in $\mathrm{CB}$ than in $\mathrm{PB}$ individuals. Under dominance action, the additive genetic variance of $\mathrm{CB}$ individuals cannot be predicted by calculating the average of the additive genetic variances of the parental lines for purebred performance and it can be larger than either of the parental genetic variances [2]. In another study that applied several genome-enabled prediction models, Tusell et al. [37] found that the estimated additive genetic variance and heritability for litter size were higher in a CB population of commercial pigs than in either of the $\mathrm{PB}$ parental lines, and suggested that it could be due to a lower level of heterozygosity of PB sows compared to CB sows. In contrast, Lutaaya et al. [29] reported a smaller additive genetic variance for backfat in a $C B$ pig line than in the PB parental lines. They attributed this result to differences in management practices, reduced genetic variation due to the fact that the selection index previously used for $\mathrm{CB}$ parents included gain and carcass traits, and to differences in sex ratios between the $\mathrm{PB}$ and $\mathrm{CB}$ populations, since most of the $\mathrm{CB}$ individuals were females.

Given the magnitude of the estimates of heritabilities and genetic correlations between $\mathrm{PB}$ and $\mathrm{CB}$ performances, the allelic frequencies between the two breeds seem to be similar and the analyzed traits do not appear to be affected by non-additive genetic effects. Regardless, the model presented here is somehow able to capture the general level of heterosis of each line into the general mean effect of each trait [13]. It would be of interest to extend this single-step terminal cross model to account for dominance effects for the analysis of traits that are more affected by non-additive genetic effects.

\section{GEN versus PED model}

The posterior mean estimates of heritability for PB performance obtained with the PED model for the different traits (Table 5) were slightly higher than those obtained with the GEN model (Table 4). This is due to the nonnormal posterior distribution of this parameter estimate with the PED model, which was more right-skewed than for the GEN model, and the lower precision that was obtained, which resulted in higher posterior mean estimates than the GEN model; frequency histograms showed that the posterior modes of this parameter were very similar between the two models. The GEN model provided more precise estimates, possibly due to the greater amount of information used, i.e. it combined genome-based relationships together with pedigreebased relationships.

Table 6 shows the mean accuracies of EBV obtained with the GEN model for $\mathrm{PB}$ and $\mathrm{CB}$ performance of the genotyped animals, i.e. the $\mathrm{PB}$ offspring and their sires, and the mean difference of these accuracies from the PED model. For all traits, EBV accuracies were higher for the GEN model than for the PED model because, to estimate EBV, the GEN model uses more information than the PED model, as explained above. Several studies have found accuracies for the EBV of genotyped animals to be higher when genomic information is included in the models compared to using pedigree data only [38, 39]. In contrast, the mean difference in accuracies of EBV between GEN and PED models for animals in the pedigree without own records and genotypes was almost equal to 0 and ranged from 0.002 to 0.008 for both $P B$ and $\mathrm{CB}$ performance. The same results were observed for the dams of the $\mathrm{CB}$ offspring because no extra information was used to estimate the EBV of these animals in the GEN model.

\section{Theoretical accuracies of EBV from the GEN model}

Scatterplots of the theoretical accuracies of EBV for PB performance versus those for $\mathrm{CB}$ performance of sires and $\mathrm{PB}$ offspring obtained with the GEN model for the different traits are in Fig. 1. Accuracies were higher for the sires than for the $\mathrm{PB}$ offspring for both $\mathrm{PB}$ and $\mathrm{CB}$ performance. This may be due to the fact that among all evaluated individuals, the sires have the largest amount of information available for both traits because they are sires of both PB and CB offspring. As expected, the accuracies of EBV were higher when the animals had records for either $\mathrm{PB}$ or $\mathrm{CB}$ performance. For the sires, this was because their EBV for $\mathrm{CB}$ performance in a terminalcross model is estimated directly through the sire genetic effect, whereas the EBV of the same sire evaluated for $\mathrm{PB}$ performance is estimated through the animal genetic effect of their PB offspring. For the PB offspring, accuracies of their EBV were much higher when evaluated for $\mathrm{PB}$ than for $\mathrm{CB}$ performance. This is because the EBV for $\mathrm{CB}$ performance of the $\mathrm{PB}$ offspring was estimated based only on records on their sires and half-sibs. This increase 
Table 5 Mean (highest posterior density interval at $95 \%$ ) of the marginal distribution of genetic parameter estimated with the pedigree-based model

\begin{tabular}{|c|c|c|c|c|c|c|c|c|}
\hline \multirow[t]{2}{*}{ Trait } & \multicolumn{8}{|l|}{ Parameter } \\
\hline & $h_{A}^{2}$ & $t_{A C}^{2}$ & $t_{B C}^{2}$ & $r g_{A, A C}$ & $p_{A}^{2}$ & $p_{C}^{2}$ & $\sigma_{A}^{2}$ & $\sigma_{C}^{2}$ \\
\hline Growth rate & $\begin{array}{l}0.33 \\
{[0.08,0.57]}\end{array}$ & $\begin{array}{l}0.24 \\
{[0.11,0.40]}\end{array}$ & $\begin{array}{l}0.29 \\
{[0.12,0.44]}\end{array}$ & $\begin{array}{l}0.79 \\
{[0.37,1.00]}\end{array}$ & $\begin{array}{l}0.13 \\
{[0.04,0.22]}\end{array}$ & $\begin{array}{l}0.09 \\
{[0.03,0.15]}\end{array}$ & $\begin{array}{l}9239 \\
{[7968.70,1,0550.00]}\end{array}$ & $\begin{array}{l}8032 \\
{[7001.20,9153.20]}\end{array}$ \\
\hline Feed conversion ratio & $\begin{array}{l}0.37 \\
{[0.21,0.56]}\end{array}$ & $\begin{array}{l}0.29 \\
{[0.14,0.45]}\end{array}$ & $\begin{array}{l}0.18 \\
{[0.06,0.32]}\end{array}$ & $\begin{array}{l}0.89 \\
{[0.66,1.00]}\end{array}$ & $\begin{array}{l}0.10 \\
{[0.03,0.18]}\end{array}$ & $\begin{array}{l}0.09 \\
{[0.03,0.16]}\end{array}$ & $\begin{array}{l}0.02 \\
{[0.02,0.03]}\end{array}$ & $\begin{array}{l}0.02 \\
{[0.02,0.02]}\end{array}$ \\
\hline Lean meat & $\begin{array}{l}0.46 \\
{[0.24,0.67]}\end{array}$ & $\begin{array}{l}0.28 \\
{[0.13,0.45]}\end{array}$ & $\begin{array}{l}0.29 \\
{[0.13,0.46]}\end{array}$ & $\begin{array}{l}0.74 \\
{[0.34,1.00]}\end{array}$ & $\begin{array}{l}0.04 \\
{[0.001,0.09]}\end{array}$ & $\begin{array}{l}0.06 \\
{[0.01,0.12]}\end{array}$ & $\begin{array}{l}2.51 \\
{[2.20,2.82]}\end{array}$ & $\begin{array}{l}3.13 \\
{[2.75,3.56]}\end{array}$ \\
\hline $\mathrm{pH}$ longissimus dorsi & $\begin{array}{l}0.46 \\
{[0.22,0.76]}\end{array}$ & $\begin{array}{l}0.27 \\
{[0.13,0.39]}\end{array}$ & $\begin{array}{l}0.11 \\
{[0.02,0.22]}\end{array}$ & $\begin{array}{l}0.91 \\
{[0.57,1.00]}\end{array}$ & - & - & $\begin{array}{l}0.02 \\
{[0.01,0.02]}\end{array}$ & $\begin{array}{l}0.02 \\
{[0.02,0.03]}\end{array}$ \\
\hline Drip loss & $\begin{array}{l}0.70 \\
{[0.52,0.89]}\end{array}$ & $\begin{array}{l}0.22 \\
{[0.09,0.38]}\end{array}$ & $\begin{array}{l}0.15 \\
{[0.03,0.28]}\end{array}$ & $\begin{array}{l}0.87 \\
{[0.58,1.00]}\end{array}$ & - & - & $\begin{array}{l}6.30 \\
{[5.52,7.20]}\end{array}$ & $\begin{array}{l}3.39 \\
{[2.98,3.85]}\end{array}$ \\
\hline Intramuscular fat & $\begin{array}{l}0.40 \\
{[0.18,0.62]}\end{array}$ & $\begin{array}{l}0.34 \\
{[0.17,0.52]}\end{array}$ & $\begin{array}{l}0.25 \\
{[0.09,0.40]}\end{array}$ & $\begin{array}{l}0.86 \\
{[0.56,1.00]}\end{array}$ & - & - & $\begin{array}{l}0.05 \\
{[0.05,0.06]}\end{array}$ & $\begin{array}{l}0.07 \\
{[0.06,0.08]}\end{array}$ \\
\hline
\end{tabular}

$h_{A}^{2}=$ purebred heritability

$t_{i C}^{2}=$ ratio of variance of the parental allelic contribution in the crossbreds ( $i=A, B$ for Piétrain and Large White line, respectively) computed as $2 \sigma_{i}^{2}\left\langle\sigma_{C}^{2}\right.$ where $\sigma_{i c}^{2}$ is the additive genetic variance of the corresponding parental alleles in the crossbreds

$r g_{A, A C}=$ genetic correlation between purebred individual and sire line contribution in the crossbreds

$p_{j}^{2}=$ ratio of variance of common pen effect

$\sigma_{j}^{2}=$ phenotypic variances $(j=A, C$ for purebred Piétrain and crossbred, respectively)

Table 6 Mean (SD) accuracy of EBV for purebred and crossbred performance obtained using single-step terminal-cross models and its difference (SD) from the mean accuracy obtained using pedigree-based terminal-cross models

\begin{tabular}{|c|c|c|c|c|c|c|c|c|}
\hline \multirow[t]{3}{*}{ Trait } & \multicolumn{4}{|c|}{ PB performance } & \multicolumn{4}{|c|}{ CB performance } \\
\hline & \multicolumn{2}{|l|}{ PB offspring } & \multicolumn{2}{|l|}{ Sires } & \multicolumn{2}{|l|}{ PB offspring } & \multicolumn{2}{|l|}{ Sires } \\
\hline & Mean & Mean difference & Mean & Mean difference & Mean & Mean difference & Mean & Mean difference \\
\hline ADG & $0.577(0.026)$ & $0.050(0.021)$ & $0.660(0.040)$ & $0.039(0.016)$ & $0.514(0.033)$ & $0.042(0.027)$ & $0.697(0.047)$ & $0.022(0.012)$ \\
\hline FCR & $0.660(0.020)$ & $0.044(0.015)$ & $0.732(0.036)$ & $0.034(0.012)$ & $0.615(0.023)$ & $0.041(0.018)$ & $0.745(0.040)$ & $0.024(0.010)$ \\
\hline LM & $0.699(0.016)$ & $0.039(0.013)$ & $0.716(0.040)$ & $0.047(0.016)$ & $0.540(0.030)$ & $0.032(0.024)$ & $0.724(0.044)$ & $0.019(0.010)$ \\
\hline $\mathrm{pH}$ & $0.639(0.024)$ & $0.046(0.018)$ & $0.745(0.039)$ & $0.027(0.011)$ & $0.624(0.025)$ & $0.045(0.018)$ & $0.750(0.040)$ & $0.025(0.011)$ \\
\hline $\mathrm{DL}$ & $0.768(0.020)$ & $0.030(0.012)$ & $0.768(0.040)$ & $0.044(0.015)$ & $0.680(0.020)$ & $0.026(0.015)$ & $0.741(0.039)$ & $0.030(0.012)$ \\
\hline IMF & $0.626(0.029)$ & $0.042(0.018)$ & $0.688(0.047)$ & $0.034(0.015)$ & $0.548(0.031)$ & $0.038(0.023)$ & $0.730(0.052)$ & $0.018(0.010)$ \\
\hline
\end{tabular}

$P B$ purebred, $C B$ crossbred, $A D G$ growth rate between end and beginning of the control period, FCR Feed conversion ratio, $L M \%$ of lean meat, $p H$ pH longissimus dorsi, $D L$ drip loss, IMF intramuscular fat

was more pronounced for traits such as ADG and IMF and less for $\mathrm{pH}$.

\section{Accuracies of EBV from the GEN_UNI model}

The mean theoretical accuracies of the EBV of sires and candidates to selection (i.e. one or two PB offspring per sire with and without own phenotype) obtained with the single-step terminal-cross model and the mean differences of these accuracies from those obtained with the two univariate single-step models (one for $\mathrm{CB}$ and the other for $\mathrm{PB}$ performance) across traits are in Table 7. Figure 2 shows scatterplots of the EBV accuracies obtained with the GEN model versus those obtained with the GEN_UNI models for sires and candidates to selection for $\mathrm{PB}$ and $\mathrm{CB}$ performance for ADG; the other traits followed a very similar pattern (not shown). Accuracies of the EBV for sires were higher when obtained with the single-step terminal-cross model than with the univariate single-step models for both $\mathrm{PB}$ and $\mathrm{CB}$ performance. Hence, accounting for $\mathrm{PB}$ and $\mathrm{CB}$ information in a two-trait model enhances the theoretical accuracy of EBV of sires for $\mathrm{PB}$ and $\mathrm{CB}$ performances. This is possibly due to the more precise variance component estimates, i.e. narrower HPD95 \%, obtained with the GEN model compared to the GEN_UNI models (not shown). Lutaaya et al. [40] reported a higher reliability of crossbred EBV of purebred animals when a terminal-cross model was used compared to a within-line model due to smaller standard 

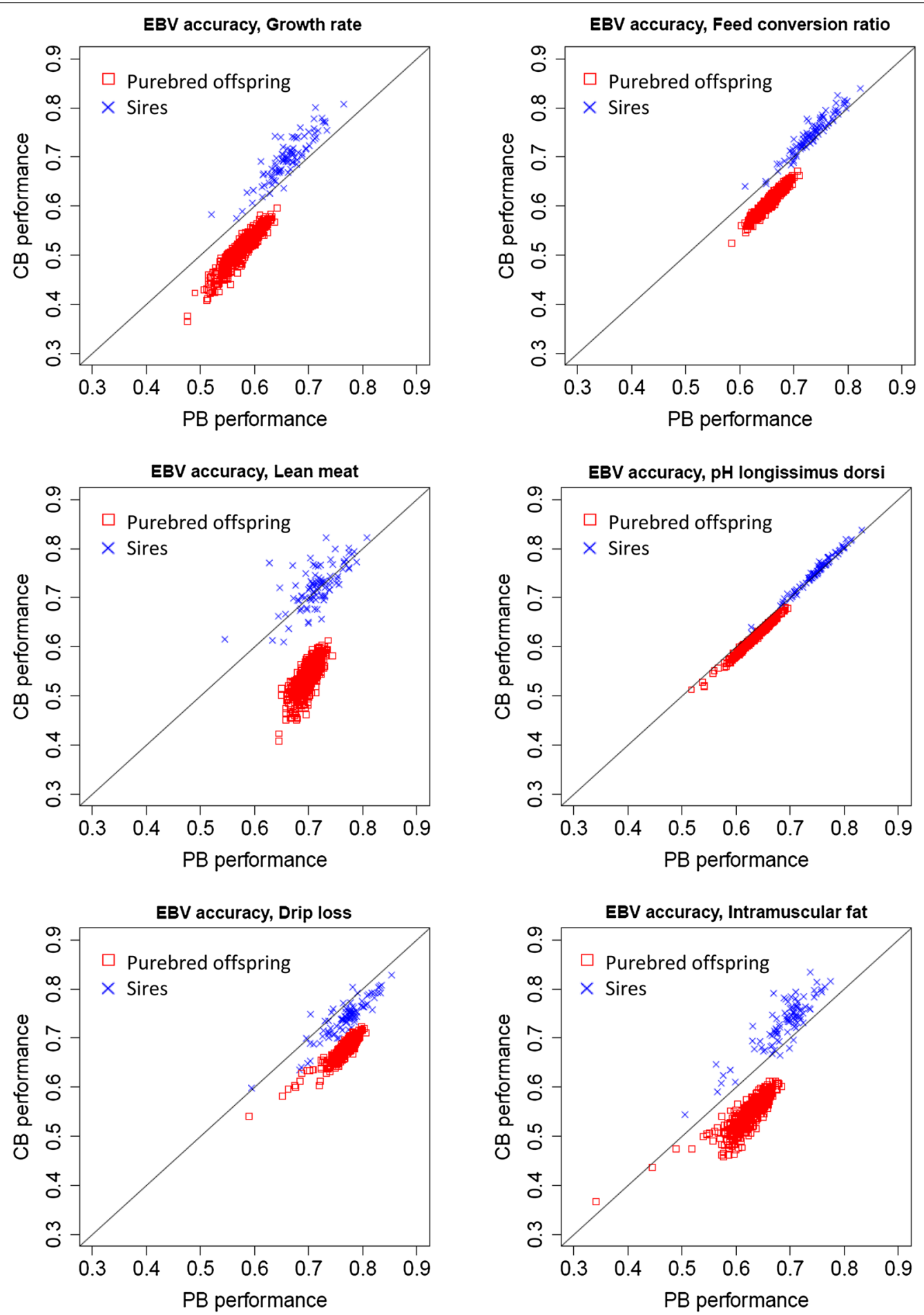

Fig. 1 Scatterplots of the accuracies of estimated breeding values for purebred versus crossbred performance obtained with single-step terminalcross models. EBV estimated breeding value, $P B$ purebred, $C B$ crossbred

errors of the variance component estimates. They stated that the terminal-cross model was more reliable because it uses all the information that is available on the progeny. Lutaaya et al. [40] highlighted the advantage of using a terminal-cross model under two scenarios: first, when EBV for both $\mathrm{PB}$ and $\mathrm{CB}$ evaluation performances are of interest and a sufficient number of $\mathrm{CB}$ records is available, and second when some traits are recorded on $\mathrm{PB}$ 
Table 7 Mean accuracy of EBV for purebred and crossbred performance obtained using single-step terminal-cross models and its difference from the mean accuracy (in parentheses) obtained using pedigree-based terminal-cross models (in parentheses)

\begin{tabular}{|c|c|c|c|c|c|c|}
\hline \multirow[t]{2}{*}{ Trait } & \multicolumn{3}{|c|}{ PB performance } & \multicolumn{3}{|c|}{ CB performance } \\
\hline & Sires & $\begin{array}{l}\text { Phenotyped } \\
\text { candidates }\end{array}$ & $\begin{array}{l}\text { Unphenotyped } \\
\text { candidates }\end{array}$ & Sires & $\begin{array}{l}\text { Phenotyped } \\
\text { candidates }\end{array}$ & $\begin{array}{l}\text { Unphenotyped } \\
\text { candidates }\end{array}$ \\
\hline$A D G$ & $0.660(0.110)$ & $0.574(0.026)$ & $0.420(0.059)$ & $0.697(0.046)$ & $0.509(0.181)$ & $0.413(0.084)$ \\
\hline FCR & $0.732(0.113)$ & $0.659(0.020)$ & $0.489(0.054)$ & $0.745(0.065)$ & $0.614(0.259)$ & $0.477(0.121)$ \\
\hline LM & $0.716(0.046)$ & $0.696(0.007)$ & $0.490(0.023)$ & $0.724(0.041)$ & $0.535(0.185)$ & $0.434(0.084)$ \\
\hline $\mathrm{pH}$ & $0.745(0.133)$ & $0.638(0.026)$ & $0.484(0.068)$ & $0.750(0.080)$ & $0.624(0.273)$ & $0.4807(0.130)$ \\
\hline $\mathrm{DL}$ & $0.768(0.046)$ & $0.768(0.005)$ & $0.535(0.024)$ & 0.741 (0.119) & $0.678(0.371)$ & $0.493(0.185)$ \\
\hline IMF & $0.688(0.105)$ & $0.625(0.019)$ & $0.450(0.053)$ & $0.730(0.040)$ & $0.547(0.184)$ & $0.442(0.078)$ \\
\hline
\end{tabular}

$P B$ purebred, $C B$ crossbred, $A D G$ growth rate between end and beginning of the control period, $F C R$ feed conversion ratio, $L M \%$ of lean meat, $p H$ pH longissimus dorsi, $D L$ drip loss, IMF intramuscular fat
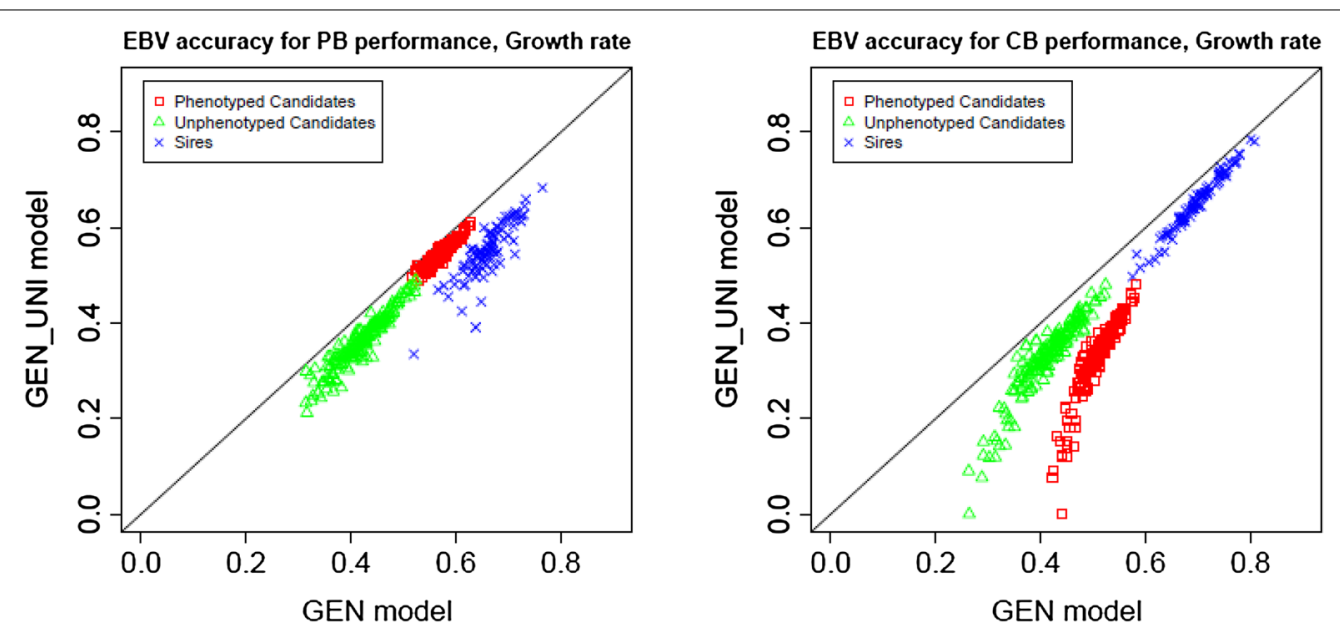

Fig. 2 Scatterplots of estimated breeding values obtained from a single-step terminal-cross model versus those from a univariate single-step models for growth rate. EBV estimated breeding value, CB crossbred, PB purebred, GEN single-step terminal-cross model, GEN_UN/ univariate single-step models for purebred or crossbred performance

animals whereas others are recorded only on $\mathrm{CB}$ animals. When PB candidates are evaluated for PB performance, the use of a terminal-cross or a univariate model does not substantially change the accuracy of their EBV. However, if the aim is to evaluate the $\mathrm{PB}$ candidates for $\mathrm{CB}$ performance, accounting for both $\mathrm{PB}$ and $\mathrm{CB}$ information greatly contributes to improving the theoretical accuracy of the EBV, especially if the selection candidates have their own phenotypes (Table 7). The latter would be advantageous for traits that are routinely evaluated in the nucleus of selection. Nonetheless, if the candidate is not phenotyped, the accuracy of the EBV obtained with the GEN model was still slightly higher than with the univariate model (Table 7). This could be of interest for genetic evaluation of traits that are not directly recorded on candidates but only on a few relatives in test stations, e.g. meat quality and carcass traits.

\section{Predictive ability}

Table 8 shows the average correlation between the predicted and yet-to-be observed $\mathrm{PB}$ and $\mathrm{CB}$ adjusted phenotypes obtained with sixfold cross-validation for all models and traits. Accounting for genomic information increased the predictive ability compared to using only pedigreebased relationships for all traits (predictive correlations for $\mathrm{PB}$ and $\mathrm{CB}$ performances were respectively $0.02-0.11$ and 0.03-0.05 higher with the GEN model than with the PED model), except for ADG, for which no increase in predictive ability was observed. Nevertheless, the joint analysis of $\mathrm{PB}$ and $\mathrm{CB}$ performance in a single-step terminal-cross model did not substantially increase the predictive ability compared to single-step univariate analyses. The predictive ability of sire EBV estimated with the univariate single-step model for $\mathrm{PB}$ performance to predict $\mathrm{CB}$ performance was equal to $0.17,0.18,0.20,0.08,0.12$ 
Table 8 Average correlation between predicted and yetto-be observed purebred and crossbred adjusted phenotypes obtained with a sixfold cross-validation

\begin{tabular}{llll}
\hline Model & Trait & PB phenotype & CB phenotype \\
\hline PED & ADG & 0.208 & 0.159 \\
& FCR & 0.139 & 0.166 \\
& LM & 0.122 & 0.148 \\
& Ph & 0.051 & 0.035 \\
& DL & 0.260 & 0.128 \\
GEN & IMF & 0.178 & 0.086 \\
& ADG & 0.204 & 0.191 \\
& FCR & 0.180 & 0.201 \\
& LM & 0.245 & 0.175 \\
& pH & 0.075 & 0.087 \\
& DL & 0.374 & 0.134 \\
GEN_UNI & IMF & 0.225 & 0.072 \\
& ADG & 0.195 & 0.191 \\
& FCR & 0.179 & 0.210 \\
& LM & 0.244 & 0.144 \\
& pH & 0.150 & 0.051 \\
& DL & 0.368 & 0.057 \\
& IMF & 0.236 & 0.051
\end{tabular}

$P B$ purebred, $C B$ crossbred, $A D G$ growth rate between end and beginning of the control period, $F C R$ feed conversion ratio, $L M \%$ of lean meat, $\mathrm{pH} \mathrm{pH}$ longissimus dorsi, $D L$ drip loss, IMF intramuscular fat

and 0.12 for ADG, FCR, LM, pH, DL and IMF, respectively. These results indicate that EBV estimated with the GEN_UNI model for PB performance predicted CB performance with the same accuracy as the models that accounted for CB performance (i.e. GEN and GEN_UNIC $\mathrm{CB}$ models). This could be due to the high estimated genetic correlations between $\mathrm{PB}$ and $\mathrm{CB}$ performance for the analyzed traits. It would be interesting in a future study to test the predictive ability of the GEN model when $\mathrm{PB}$ and $\mathrm{CB}$ performance are less genetically correlated (e.g. when purebreds are raised in selection nucleus and crossbreds under field conditions, or for traits that are strongly influenced by non-additive genetic effects).

\section{Practical implications}

Routine genetic evaluations in Piétrain pigs (as well as in other PB pig sire lines) are usually performed with pedigree-based BLUP using phenotypes of selection candidates and, for some traits, using phenotypes recorded on relatives obtained from test stations. Although selection is implemented within PB lines, the ultimate aim is to improve $\mathrm{CB}$ performance under field conditions. If the genetic correlations between $\mathrm{PB}$ and $\mathrm{CB}$ performance differ from 1, incorporating $\mathrm{CB}$ and genomic information into the genetic evaluation of the PB lines can contribute to increase genetic gains.
To the best of our knowledge, this is the first implementation of a single-step terminal-cross model using $\mathrm{PB}$ sire genotypes to model $\mathrm{CB}$ performance and its application to real data for a wide range of traits. Christensen et al. [13] developed a more complex single-step method for the genomic evaluation of $\mathrm{PB}$ and $\mathrm{CB}$ performance. Their model makes full use of genotypes on $\mathrm{CB}$ individuals and therefore accounts for the exact contribution of alleles of the sire and the dam to a given $\mathrm{CB}$ performance. Further research should compare their model with the GEN model with respect to their ability to predict new data, i.e. candidates to selection without phenotypic records. It is also necessary to determine whether the extra genetic progress achieved with our model overcomes the additional expenses of its implementation under commercial conditions, which would require substantial organizational changes in the breeding scheme, such as collecting phenotypes on the $\mathrm{CB}$ offspring, i.e. piglet production records collected from multiple commercial farms, genotyping selection candidates and tracing the pedigree to connect crossbreds with purebreds. Availability of the PB phenotype would be advantageous. Nonetheless, the main advantage of the GEN model is that CB genotypes would not be needed, which would limit extra expenses, and the dam contribution could be accounted for in the model as a permanent environmental effect.

\section{Conclusions}

We proposed and applied on real data a single-step terminal-cross model that accounts for genomic information on $\mathrm{PB}$ individuals and uses $\mathrm{CB}$ performance to estimate genetic parameters of several production and quality traits in pigs. Accounting for $\mathrm{PB}$ and $\mathrm{CB}$ information, along with genomic information, improves the theoretical accuracy of genetic evaluations in breeding programs that are based on crossbreeding. Including genomic information increased predictive abilities compared to using pedigree information only, but the single-step terminal-cross model did not outperform the predictive performance of univariate single-step models for $\mathrm{PB}$ and $\mathrm{CB}$ performance. The implementation of the proposed single-step terminal-cross model is straightforward with available software but its use under field conditions needs to be further addressed in terms of predictive ability, genetic progress achieved, and costs.

\section{Authors' contributions}

LT designed, carried out the analyses and drafted the manuscript; HG defined the experimental protocol and provided critical insights; JR defined the experimental protocol; AL helped in implementing the analyses and provided critical insights; MJM defined the experimental protocol, coordinated the production and management of the animals and provided critical insights; $\mathrm{CL}$ defined the experimental protocol, designed the analyses and provided critical insights. All authors read and approved the final manuscript. 


\section{Author details}

${ }^{1}$ GenPhySE, Université de Toulouse, INRA, INPT, INP-ENVT, Castanet Tolosan, France. ${ }^{2}$ IFIP - Institut du porc, La Motte au Vicomte, BP 35104, 35651 Le Rheu Cedex, France.

\section{Acknowledgements}

The authors acknowledge funding from the UtOplGe ANR-10-GENOM_BTV015 project and the INRA SelGen metaprogram projects (SelDir and X-Gen) and BIOPORC. The authors are grateful to the French breeding companies of the Bioporc group (ADN, Choice Genetics France, Gene+, Nucléus) for providing the animals and to the staff of the test station of Le Rheu for collecting the data. We are also grateful to the Genotoul bioinformatics platform Toulouse Midi-Pyrenees for providing computing and storage resources, and to Ignacy Misztal and coworkers for the blupf90 suite of programs.

\section{Competing interests}

The authors declare that they have no competing interests.

Received: 3 July 2015 Accepted: 31 March 2016

Published online: 07 April 2016

\section{References}

1. Merks JWM. Genetic improvement at the commercial level compared to genetic progress at the nucleus level. In: Proceedings of the 2001 national swine improvement federation annual meeting, 7 December 2001; St Louis. 2001. p. 26.

2. Wei M, van der Werf JH. Genetic correlation and heritabilities for purebred and crossbred performance in poultry egg production traits. J Anim Sci. 1995;73:2220-6

3. Comstock RE, Robinson HF, Harvey PH. A breeding procedure designed to make maximum use of both general and specific combining ability. Agron J. 1949;41:360-7.

4. Dekkers JCM. Marker-assisted selection for commercial crossbred performance. J Anim Sci. 2007;85:2104-14.

5. Ibáñez-Escriche N, Reixach J, Lleonart N, Noguera JL. Genetic evaluation combining purebred and crossbred data in a pig breeding scheme. J Anim Sci. 2011;89:3881-9.

6. Wei $\mathrm{M}$, van der Werf $\mathrm{JHJ}$. Maximizing genetic response in crossbreds using both purebred and crossbred information. Anim Sci. 1994:59:401-13.

7. Metayer A, Daumas G. Estimation, par découpe, de la teneur en viande maigre des carcasses de porc. Journées Recherche Porcine. 1998;30:7-11.

8. Daumas G. Taux de muscle des pièces et appréciation de la composition corporelle des carcasses. Journées Recherche Porcine. 2008:40:61-7.

9. Davenel A, Bazin C, Quellec S, Challois S, Gispert M, Mercat MJ, et al. Dosage haut débit des lipides intramusculaires de la viande de porc par imagerie par résonance magnétique. Journées Recherche Porcine. 2012;44:53-4.

10. Legarra A, Aguilar I, Misztal I. A relationship matrix including full pedigree and genomic information. J Dairy Sci. 2009;92:4656-63.

11. Misztal I, Legarra A, Aguilar I. Computing procedures for genetic evaluation including phenotypic, full pedigree, and genomic information. J Dairy Sci. 2009;92:4648-55.

12. Christensen OF, Lund ML. Genomic prediction when some animals are not genotyped. Genet Sel Evol. 2010;42:2.

13. Christensen OF, Madsen P, Nielsen B, Su G. Genomic evaluation of both purebred and crossbred performances. Genet Sel Evol. 2014;46:23.

14. Henderson CR. Best linear unbiased estimat ion and prediction under a selection model. Biometrics. 1975;31:423-47.

15. Aguilar I, Misztal I, Johnson DL, Legarra A, Tsuruta S, Lawlor TJ. Hot topic: a unified approach to utilize phenotypic, full pedigree, and genomic information for genetic evaluation of Holstein final score. J Dairy Sci. 2010;93:743-52.

16. Van Raden PM. Efficient methods to compute genomic predictions. J Dairy Sci. 2008;91:4414-23.
17. Christensen OF, Madsen P, Nielsen B, Ostersen T, Su G. Single-step methods for genomic evaluation in pigs. Animal. 2012;6:1565-71.

18. Misztal I. Complex models, more data: simpler programming. Interbull Bull. 1999:20:33-42.

19. Raftery AE, Lewis S. How many iterations in the Gibbs sampler? In: Bernardo JM, Berger JO, Dawid AP, Smith AFM, editors. Bayesian statistics, vol. 4. Oxford: Oxford Univ. Press; 1992. p. 763-73.

20. Geweke J. Evaluating the accuracy of sampling-based approaches to the calculation of posterior moments? In: Bernardo JM, Berger JO, Dawid AP, Smith AFM, editors. Bayesian statistics, vol. 4. Oxford: Oxford Univ. Press; 1992. p. 169-93.

21. Aguilar I, Misztal I. Technical note: recursive algorithm for inbreeding coefficients assuming nonzero inbreeding of unknown parents. J Dairy Sci. 2008;91:1669-72.

22. Clutter AC. Genetics of performance traits. In: Rothschild MF, Ruvinsky A, editors. The genetics of the pig. 2nd ed. Wallingford: CAB International; 2011. p. 325-54.

23. Ciobanu DC, Lonergan SM, Huff-Lonergan EJ. Genetics of meat quality and carcass traits. In: Rothschild MF, Ruvinsky A, editors. The genetics of the pig. 2nd ed. Wallingford: CAB International; 2011. p. 355-89.

24. Solanes FX, Reixach J, Tor M, Tibau J, Estany J. Genetic correlations and expected response for intramuscular fat content in a Duroc pig line. Livest Sci. 2009;123:63-9.

25. Hernández-Sánchez J, Amills M, Pena RN, Mercadé A, Manunza A, Quintanilla R. Genomic architecture of heritability and genetic correlations for intramuscular and back fat contents in Duroc pigs. J Anim Sci. 2013;91:623-32

26. Clutter AC. Genetics of meat quality and carcass traits. In: Rothschild MF, Ruvinsky A, editors. The genetics of the pig. 2nd ed. London: CAB International; 2011. p. 355-89.

27. Falconer DS, Mackay TFC. Correlated characters. In: Introduction to quantitative genetics. 4th ed. Harlow, UK: Longman Scientific \& Technical, Burnt Mill; 1996. p. 312-34.

28. Bösch M, Rohe R, Looft H, Kalm E. Selection on purebred and crossbred performance for litter size in pigs. Arch Tierz. 2000;43:249-62.

29. Lutaaya E, Misztal I, Mabry JW, Short T, Timm HH, Holzbauer R. Genetic parameter estimates from joint evaluation of purebreds and crossbreds in swine using the crossbred model. J Anim Sci. 2001;79:3002-7.

30. Lo LL, Fernando RL, Grossman M. Covariance between relatives in multibreed populations: additive model. Theor Appl Genet. 1993;87:423-30.

31. Wei M, van der Steen HAM. Comparison of reciprocal recurrent selection with pure-line selection systems in animal breeding (a review). Anim Breed Abstr. 1991;59:281-98.

32. Kinghorn BP, Swan AA. A multitrait approach for data involving genotype $\times$ environment interaction. J Anim Breed Genet. 1991;108:111-5.

33. Spilke J, Groeneveld E, Mielenz N. Joint purebred and crossbred (co)variance component estimation with a pseudo multiple trait model: loss in efficiency. J Anim Breed Genet. 1998;115:341-50.

34. Wei M, Van der Steen HAM, van der Werf JHJ, Brascamp EW. Relationship between purebred and crossbred parameters. J Anim Breed Genet. 1991;108:253-61.

35. Brun JM. Interactions géniteur x population des partenaires III. Synthèse bibliographique. Genet Sel Evol. 1985;17:561-78.

36. Zumbach B, Misztal I, Tsuruta S, Holl J, Herring W, Long T. Genetic correlations between two strains of Durocs and crossbreds from differing production environments for slaughter traits. J Anim Sci. 2007;85:901-8.

37. Tusell L, Pérez-Rodríguez P, Forni S, Wu XL, Gianola D. Genome-enabled methods for predicting litter size in pigs: a comparison. Animal. 2013;7:1739-49.

38. Van Raden PM, Van Tassell CP, Wiggans GR, Sonstegard TS, Schnabel RD, Taylor JF, et al. Invited review: reliability of genomic predictions for North American Holstein bulls. J Dairy Sci. 2009;92:16-24.

39. Forni S, Aguilar I, Misztal I. Different genomic relationship matrices for single-step analysis using phenotypic, pedigree and genomic information. Genet Sel Evol. 2011;43:1.

40. Lutaaya E, Misztal I, Mabry JW, Short T, Timm HH, Holzbauer R. Joint evaluation of purebreds and crossbreds in swine. J Anim Sci. 2002;80:2263-6. 